\title{
Hand-Foot and Mouth syndrome with Capecitabine
}

\section{Issam Lalya* and Hamid Mansouri}

Department of Radiation Oncology, Military Teaching Hospital of Rabat, Mohammed V University, Rabat-Morocco

"Corresponding Author: Issam Lalya, Department of Radiation Oncology, Military Teaching Hospital of Rabat, Mohammed $\vee$ University, Rabat, Morocco, Tel: 00212661572770; E-mail: issamlalya@yahoo.fr

Rec date: February 21,2016 Acc date: February 24,2016 Pub date: February 26,2016

Copyright: (c) 2016 Issam L, et al. This is an open-access article distributed under the terms of the Creative Commons Attribution License, which permits unrestricted use, distribution, and reproduction in any medium, provided the original author and source are credited.

\section{Clinical Image}

A 33-year-old woman presented with anal squamous cell carcinoma staged T2N1M0, she underwent radiation therapy with concomitant Capecitabine administered orally at a dose of $825 \mathrm{mg} / \mathrm{m} 2$ twice a day throughout the course of radiation. Three weeks after initiation of treatment she presented with hyperpigmentation involving the dorsum and the bottom of both hands and feet, with reinforcement over the knuckles and toes (Figures 1,2).

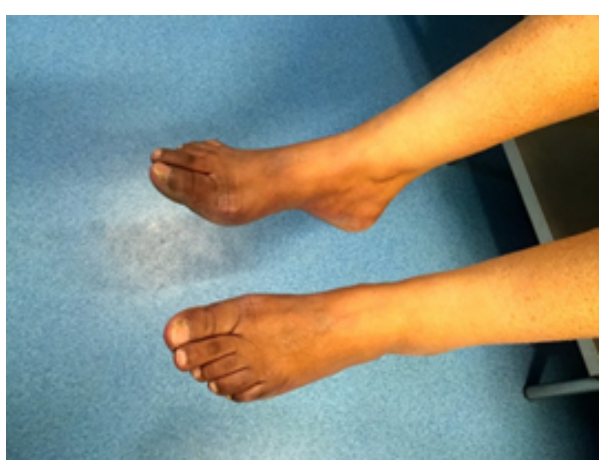

Figure 1: Feet hyperpigmentation.

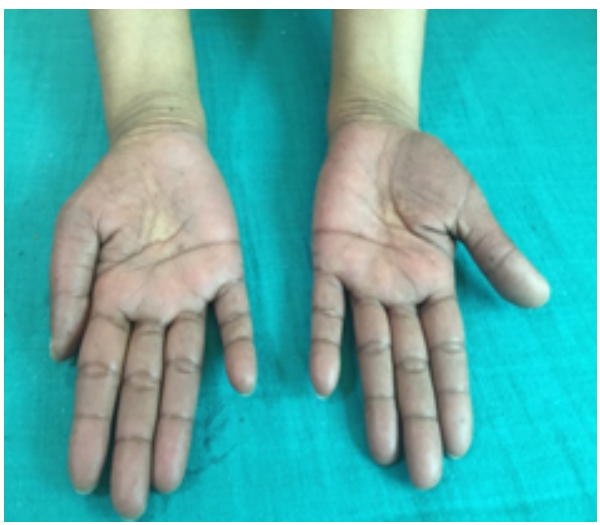

Figure 2: Hyperpigmentation and erythema of both hands.
Careful examination of the palms showed erythema underlying the hyperpigmentation. We retained the diagnosis of palmar-plantar erythrodysesthesia (the hand-foot syndrome). The peculiar case of this patient is the involvement of the dorsum of the tongue with patchy and confluent hyperpigmentation without ulceration (Figures 3,4).

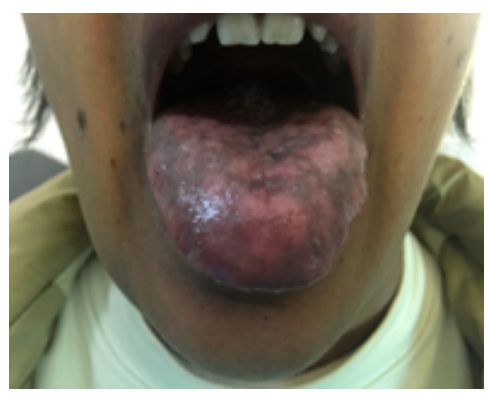

Figure 3: Hyperpigmentation of the dorsum of the tongue.

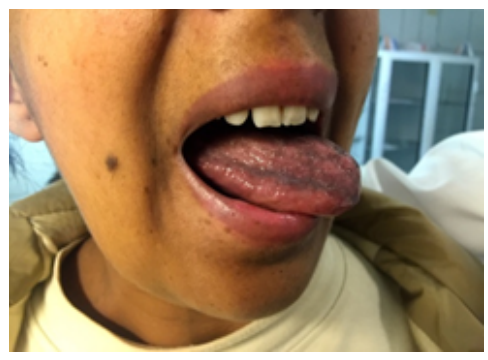

Figure 4: Hyperpigmentation of the dorsum of the tongue.

Treatment with topical agents was initiated without interrupting Capecitabine.One month after the end of treatment, all of the above described lesions completely resolved. To the best of our knowledge this is the first case of Hand-Foot syndrome associated to hyperpigmentation of the tongue. 